\title{
Review Article \\ Perspectives on Peripheral Neuropathy as a Consequence of Metformin-Induced Vitamin B12 Deficiency in T2DM
}

\author{
Marwan A. Ahmed, ${ }^{1}$ George L. Muntingh, ${ }^{1}$ and Paul Rheeder ${ }^{2}$ \\ ${ }^{1}$ Department of Pharmacology, Faculty of Health Sciences, University of Pretoria, Pretoria, South Africa \\ ${ }^{2}$ Department of Internal Medicine, Steve Biko Academic Hospital, University of Pretoria, Pretoria, South Africa \\ Correspondence should be addressed to Marwan A. Ahmed; mrwnwd@yahoo.com
}

Received 8 May 2017; Accepted 31 July 2017; Published 27 August 2017

Academic Editor: Ilias Migdalis

Copyright (c) 2017 Marwan A. Ahmed et al. This is an open access article distributed under the Creative Commons Attribution License, which permits unrestricted use, distribution, and reproduction in any medium, provided the original work is properly cited.

Peripheral neuropathy $(\mathrm{PN})$ is a primary complication of type 2 diabetes mellitus (T2DM) and a direct manifestation of vitamin B12 deficiency. Examining the effects of metformin use on PN status became imperative following clinical studies that showed the vitamin B12-lowering effect of the medication. The complexity of the topic and the inconsistency of the results warrant consideration of topic-specific perspectives for better understanding of the available evidence and more appropriate design of future studies.

\section{Introduction}

T2DM is a metabolic disorder that is increasingly becoming a public health concern. The disease is associated with a variety of systemic macrovascular and microvascular complications. Diabetic peripheral neuropathy (DPN) is the most common complication, and it may eventually develop in up to $50 \%$ of patients [1]. DPN is associated with ulcerations, recurrent foot infections, Charcot's joints, foot or ankle fractures, amputations, and depression. As a result, DPN can cause physical limitations, increased utilization of health care, and diminished work productivity [2]. Gordois et al. estimated the annual expenditure on DPN in the United States to be between 4.6 and 13.7 billion dollars [3]. In addition, 27\% of diabetes-related medical costs are attributable to DPN [3].

Both American and European guidelines recommend metformin as the first-line agent for the pharmacological management of T2DM. Accumulating evidence suggests that long-term use of metformin is associated with low vitamin B12 levels, and findings from both observational and interventional studies have confirmed this association [4-8]. Recent American Diabetes Association (ADA) guidelines recommend periodic testing of vitamin B12 in metformin-treated patients, especially in those with peripheral neuropathy [9].
Since vitamin B12 is essential for the remethylation of homocysteine to methionine, metformin-induced vitamin B12 deficiency could be associated with hyperhomocysteinemia, a condition with a questionable detrimental impact on macrovascular disease in T2DM patients [10]. The clinical presentation of vitamin B12 deficiency generally includes haematological and neurological manifestations. Neuropathy can be the only manifestation of the deficiency, without a haematologic presentation [11]. Over the last few decades, the clinical manifestations of vitamin B12 deficiency have shown notable trends towards neurological signs and symptoms [12]. PN resulting from vitamin B12 deficiency is clinically indistinguishable from DPN [13]. Such PN neuropathy can be asymptomatic [12] and could likely worsen DPN in diabetic patients. It is reasonable to assume that PN resulting from metformin-associated vitamin B12 deficiency has a significant risk of being misdiagnosed as DPN. Longterm metformin use can theoretically cause or worsen PN in diabetes patients, adding to its considerable burden.

The potential for metformin-induced vitamin B12 deficiency to cause or worsen DPN has recently been investigated by several studies with conflicting findings. This article provides new perspectives that may assist in interpreting the available evidence and give a deeper understanding of the topic for the design of future research. 


\section{The Current Evidence}

The potential association between metformin use and vitamin B12 deficiency reported by interventional and observational studies has enabled researchers to question whether such an association can have clinical implications. Recently, the topic has attracted attention, and several studies were conducted to investigate the potential for metformin-induced vitamin B12 deficiency to cause, or worsen, PN in T2DM patients.

The insidious nature of neuropathy makes clinical trials and cohort studies impractical to investigate the possible relationship between metformin use and worsening of PN in T2DM patients [14]. Ethical, sample size, and study duration considerations oppose utilizing clinical trials to answer the question [14]. Despite their questionable validity and known limitations, cross-sectional and case-control studies seem to be the most convenient for studying the relationship. Thus, all of the available evidence comes from such studies. The results were conflicting and studies have shown differences in designs and settings (Table 1). Neuropathy was assessed by different tools with various degrees of subjectivity, and all studies had relatively small sample sizes (Table 1).

\section{Antineuropathic and Neuroprotective Effects of Metformin}

Animal studies have recently shown that metformin can exert neuroprotective and antineuropathic activities that are independent of its euglycemic effect. Metformin protects against numbness and neuropathic pain induced by chemotherapy in mice [21]. The sensory symptoms of pain, dysaesthesia, and paraesthesia characterize both diabetic PN and chemotherapy-induced $\mathrm{PN}$, signifying the impact of these findings. Animal studies have also reported that metformin abolished pain resulting from the activation of sensory neurons [22] as well as resolved neuropathic allodynia [23], protected against ethanol-induced neuronal apoptosis [24], and enhanced neurogenesis [25]. It also suppressed cortical neuronal apoptosis [26] and exerted neuroprotective effects in Parkinson's disease [27]. Clinically, a retrospective chart review also reported the association between metformin use and a decrease in lumbar radiculopathy pain [28]. Antineuropathic effects of metformin may be mediated by $5^{\prime}$ adenosine monophosphate-activated protein kinase (AMPK) activation [29]. Impaired AMPK signaling was linked to PN in animals [30].

The glycemic control-independent neuroprotective effect of metformin may add a new perspective to $\mathrm{PN}$ due to metformin-induced vitamin B12 deficiency [14]. Given the above evidence, metformin can influence PN in two ways, excluding that related to glycemic control. It may exert a positive neuroprotective effect, or it may enhance PN by inducing vitamin B12 deficiency. The results showing no association between vitamin $\mathrm{B} 12$ and $\mathrm{PN}$ do not preclude the ability of metformin to exert negative effects on PN status by lowering vitamin B12 levels. The vitamin B12 deficiency-mediated effects may blunt the antineuropathic, neuroprotective, and euglycemic actions, which partly blunt the medication's additional beneficial actions in PN.
The theory may provide deeper insight into the contradicting results of studies investigating PN in metformin-treated T2DM patients. The inconsistency of results may be attributed to variation in the individual weights of metformin's direct impact on the neurons, its metabolic euglycemic effect, and its vitamin B12 deficiency-mediated neuropathic effect. It can be hypothesized that the findings in each study reflect the dominant action of metformin in that particular population. The sample and study characteristics, such as the mean age, duration of diabetes, metformin dose, and duration as well as race and comorbidities, may contribute to the dominance of certain axes and to the net impact of metformin on PN.

\section{Study Design and Methodological Issues}

Factors within clinical practice might have methodological impacts that deserve consideration when interpreting the evidence on PN resulting from metformin-associated vitamin B12 deficiency [14]. Both American and European guidelines recommend using metformin as a first-line medication for T2DM. Encountering T2DM patients who are not on metformin is uncommon. Metformin users and nonusers are anticipated to be inherently different in observational studies that compare the two groups. Obtaining similar study groups can become unattainable by having one group with the "abnormality" of not taking metformin. The highly probable and adherent imbalance between the two comparison groups makes it unclear whether metformin use has played the primary role in the outcome and worsening of PN. In other words, factors distributed differentially between the two groups can provide alternative explanations for the findings, thus threatening the study validity. A control group may discredit the validity in studies aiming at investigating the effect of metformin-induced vitamin B12 deficiency on PN. Even comparison groups can only be attained by randomization in controlled trials, and such study designs are impractical to answer this question.

Considering the antineuropathic and neuroprotective actions of metformin also gives us a different view regarding the designs of studies aiming at exploring the relationship between medication use and PN. In the metformin group, there is a possibility that the medication's antineuropathic and neuroprotective effects predominate or dilute its vitamin B12 deficiency-mediated neuropathic impact. Thus, comparing $\mathrm{PN}$ in the metformin and nonmetformin groups could produce distorted conclusions that do not reflect the real contribution of metformin-induced vitamin B12 deficiency to $\mathrm{PN}$. This perspective adds strength to the studies that compared vitamin B12-normal and -deficient patients using metformin and discredits the classical designs comparing metformin users and nonusers.

\section{An Emerging Theory on Metformin-Induced Vitamin B12 Deficiency}

Vitamin B12 is involved in both methylmalonyl-CoA mutase and methionine synthase intracellular pathways. Vitamin B12 deficiency interferes with the two pathways and causes increased levels of methylmalonic acid and homocysteine, 
TABle 1: Settings, designs, and results of studies that investigated the impact of metformin-induced low vitamin B12 on peripheral neuropathy in T2DM patients.

\begin{tabular}{|c|c|c|c|}
\hline Study & Setting & Design & Results \\
\hline Wile and Toth [15] & $\begin{array}{l}\text { Neuromuscular clinic at } \\
\text { a university hospital, } \\
\text { Canada }\end{array}$ & $\begin{array}{l}\text { Case-control study. Cases were } \\
\text { T2DM patients on metformin } \\
\text { with primary diagnosis } \\
\text { of PN ( } 59 \text { participants). Controls } \\
\text { were T2DM patients not taking } \\
\text { metformin with primary } \\
\text { diagnosis of PN ( } 63 \text { participants). }\end{array}$ & $\begin{array}{l}\text { The metformin group had more } \\
\text { severe PN (assessed by TCSS and NIS). } \\
\text { Electrophysiological markers showed } \\
\text { no significant difference between the two } \\
\text { groups. Cumulative metformin dose } \\
\text { showed a significant positive correlation } \\
\text { with TCSS scores }(\text { rho }=0.80 \text { ) and } \\
\text { NIS scores }(\mathrm{rho}=0.79) .\end{array}$ \\
\hline Singh et al. [16] & $\begin{array}{l}\text { Internal medicine clinic } \\
\text { in a tertiary hospital, India }\end{array}$ & $\begin{array}{l}\text { Cross-sectional study. Randomly } \\
\text { selected T2DM patients were } \\
\text { divided into metformin users } \\
\text { (84 participants) and nonusers } \\
\text { (52 participants). }\end{array}$ & $\begin{array}{l}\text { The metformin group had more } \\
\text { severe PN (assessed by TCSS). } \\
\text { Cumulative metformin dose } \\
\text { revealed a significant } \\
\text { positive correlation with } \\
\text { TCSS (rho }=0.53 \text { ). }\end{array}$ \\
\hline $\begin{array}{l}\text { de Groot-Kamphuis } \\
\text { et al. [17] }\end{array}$ & $\begin{array}{l}\text { Secondary care outpatient } \\
\text { diabetes clinic, } \\
\text { the Netherlands }\end{array}$ & $\begin{array}{l}\text { Cross-sectional study. Randomly } \\
\text { selected T2DM patients were } \\
\text { divided into metformin users } \\
\text { (164 participants) and nonusers } \\
\text { (134 participants). }\end{array}$ & $\begin{array}{l}\text { Prevalence of neuropathy } \\
\text { (obtained from records) was } \\
\text { significantly lower in the } \\
\text { metformin group. }\end{array}$ \\
\hline Chen et al. [13] & $\begin{array}{l}\text { Diabetes clinic of a } \\
\text { tertiary hospital, UK }\end{array}$ & $\begin{array}{l}\text { Cross-sectional study. Randomly } \\
\text { selected T2DM patients were } \\
\text { divided into metformin users } \\
\text { (152 participants) and nonusers } \\
\text { (50 participants). }\end{array}$ & $\begin{array}{l}\text { All PN-assessing tools } \\
\text { (monofilament, neurothesiometry, } \\
\text { NTSS-6, and s-LANSS) showed } \\
\text { no significant differences } \\
\text { between the two groups. }\end{array}$ \\
\hline Biemans et al. [18] & $\begin{array}{l}\text { Four primary care centers, } \\
\text { the Netherlands }\end{array}$ & $\begin{array}{l}\text { Cross-sectional study. } \\
\text { Metformin-treated } \\
\text { T2DM patients were divided into } \\
\text { the vitamin B12-deficient } \\
\text { (126 participants) and normal } \\
\text { (322 participants) groups. }\end{array}$ & $\begin{array}{l}\text { There were no significant differences } \\
\text { in PN (assessed by MNSI and } \\
\text { extracted from records) between } \\
\text { the two groups. }\end{array}$ \\
\hline Russo et al. [19] & $\begin{array}{c}\text { Diabetes clinic of a university } \\
\text { hospital, Italy }\end{array}$ & $\begin{array}{l}\text { Cross-sectional study. T2DM } \\
\text { patients were divided into } \\
\text { metformin users ( } 124 \text { participants) } \\
\text { and nonusers ( } 139 \text { participants). }\end{array}$ & $\begin{array}{l}\text { There was no significant difference } \\
\text { in prevalence of PN between the } \\
\text { two groups. PN was suspected } \\
\text { based on abnormalities of certain } \\
\text { evaluations and confirmed } \\
\text { by NCVs. }\end{array}$ \\
\hline Roy et al. [20] & Tertiary Hospital, India & $\begin{array}{l}\text { Cross-sectional study. T2DM } \\
\text { patients were divided into ( } 1 \text { ) the } \\
\text { metformin group ( } 35 \text { participants), } \\
\text { ( } 2 \text { ) the metformin + other } \\
\text { antihyperglycemic group } \\
\text { ( } 20 \text { participants), and (3) the } \\
\text { nonmetformin group (35participants). }\end{array}$ & $\begin{array}{c}\text { Neuropathy (assessed by NCVs) } \\
\text { did not differ significantly between } \\
\text { the groups. }\end{array}$ \\
\hline Ahmed et al. [14] & $\begin{array}{l}\text { Diabetes clinics of } \\
\text { two tertiary } \\
\text { hospitals, South Africa }\end{array}$ & $\begin{array}{c}\text { Cross-sectional study. } \\
\text { Metformin-treated } \\
\text { T2DM patients were divided into } \\
\text { the vitamin B12-deficient } \\
\text { (34 participants) and normal } \\
\text { (87 participants) groups. }\end{array}$ & $\begin{array}{l}\text { There was no difference in the } \\
\text { presence of PN (assessed by NTSS- } 6 \text { ) } \\
\text { between the two groups. Levels of } \\
\text { vitamin B12 and NTSS- } 6 \text { scores } \\
\text { were not correlated. }\end{array}$ \\
\hline
\end{tabular}

MNSI: Michigan Neuropathy Screening Instrument; NCVs: nerve conduction velocities; NIS: Neuropathy Impairment Score; NTSS-6: Neuropathy Total Symptom Score-6; PN: peripheral neuropathy; rho: Spearman's rank correlation coefficient; s-LANSS: Self-administered Leeds Assessment of Neuropathic Symptoms and Signs; TCSS: Toronto Clinical Scoring System.

which are also considered as biochemical indicators of cellular (metabolic) vitamin B12 deficiency [31]. The increase in homocysteine concentration can also be a result of folic acid deficiency [31].
The theory that metformin only lowers the circulating vitamin B12 without affecting the intracellular vitamin levels was recently introduced [32]. This theory is based on the fact that low vitamin B12 status should result in increased levels 
of the biochemical indicators of metabolic deficiency. Clinical studies, which reported nonelevated concentrations of methylmalonic acid and homocysteine among metformintreated patients, constitute the framework of the theory. Reinstatler et al. found that despite their significantly lower levels of vitamin B12, metformin users had lower concentrations of homocysteine when compared to nonusers [33]. As the study was conducted after the commencement of the folic acid fortification in the United States, homocysteine levels carried more diagnostic specificity in assessing vitamin B12 status. The theory also relies on the controlled trial of de Jager et al. which found no significant increase in homocysteine concentrations despite low vitamin B12 levels in the metformin group when studied over a period of 4.3 years [4]. Greibe et al. reported that a six-month treatment with metformin resulted in lower serum vitamin B12 without an impact on MMA in women with polycystic ovary syndrome [34]. The authors took a step further and measured vitamin B12 bound to haptocorrin, a transporter that binds $70 \%$ to $80 \%$ of the circulating vitamin forming a metabolically inert complex. The results showed a reduction in haptocorrin-bound vitamin levels in the metformin group. They concluded that metformin-induced low vitamin B12 levels resulted from the decrease in B12haptocorrin fraction and did not reflect a true metabolic deficiency. An animal study has also reported increased liver accumulation and decreased circulating concentrations of vitamin B12 in rats following subcutaneous administration of metformin [35]. The authors proposed that metformin enhanced redistribution of vitamin B12 rather than affecting its cellular status.

Adopting the above theory would mean that metformin does not cause or worsen PN in diabetic patients. However, substantial evidence contradicts the theory. The difference in homocysteine levels in the metformin and nonmetformin groups was not statistically significant in the study of Reinstatler et al. [33]. The trial of de Jager et al. indeed reported that metformin caused a slight increase of 5\% in homocysteine levels. The $p$ value was 0.09 , which may indicate a borderline significant trend. The trial's authors attributed the nonsignificance to the relatively low numbers of patients with vitamin B12 deficiency, and they expected the homocysteine levels to show further increases with a longer treatment duration [4]. Moreover, the six-month period of metformin use in a study by Greibe et al. did not seem to be sufficient to deplete vitamin B12 stores and consequently result in elevated MMA or homocysteine levels. Most importantly, the association between metformin use and the increased levels of cellular vitamin B12 biomarkers was reported by many studies [15, 20, 36-38]. Moving to clinical practice, the aim of clinical research, accepting the theory that metformin only reduces circulating B12 and not its intracellular levels, may take us to another level and raises a crucial question on the validity of the current vitamin B12 serum test. Adopting this theory dictates a revolutionary approach in testing B12 in clinical settings. The theory, however, raises the importance of showing the potential of metformin to cause cellular vitamin B12 deficiency as an achievable initial goal of future research.

\section{Other Perspectives}

The clinical trial of de Jager et al. has shown that longterm metformin treatment gradually lowered the levels of vitamin B12 [4]. Thus, the possible development of PN due to metformin-induced vitamin B12 deficiency is anticipated to be insidious and progressive. Long periods of treatment with metformin in studies with sufficiently large sample sizes may be required to reveal a detectable and statistically significant PN.

Vitamin B12 levels may differ in various ethnic groups. Several studies reported higher concentrations of vitamin B12 in black individuals when compared to white individuals [39-41]. This is attributed to higher levels of vitamin B12-binding proteins in the black populations [42]. We have recently reported higher concentrations of the vitamin among black South African T2DM patients on metformin [14]. To our knowledge, the impact of ethnicity on the cellular status of the vitamin is not yet investigated. Currently, utilized cutoff points and definitions of vitamin B12 deficiency do not consider the possible effects of ethnicity. Ethnicity should be taken into consideration as a contributing factor when studying $\mathrm{PN}$ as a clinical consequence of metformin-induced vitamin B12 deficiency.

\section{Conclusion}

The conflicting results of the available evidence reflect the complexity of linking metformin-induced vitamin B12 deficiency and PN in T2DM patients, where the disease state also induces neuropathies. Different perspectives can be considered in interpreting and designing studies attempting to explore the triangle of metformin, vitamin $\mathrm{B} 12$, and $\mathrm{PN}$ in T2DM. The glycemic control-independent neuroprotective and antineuropathic effects of metformin recently reported in animal studies may explain the contradicting nature of the obtained results and enhance understanding of the topic. Obtaining similar study groups is probably unachievable in observational studies that compare metformin users and nonusers, which blunts their validity and raises questions about most of the available evidence.

Future research should probably first focus on confirming metformin's potential to cause vitamin B12 metabolic deficiency. Studies with sufficiently large sample sizes and proper designs that utilize more objective, and conventional, $\mathrm{PN}$-assessing tools are required to investigate the relationship between metformin use and PN in T2DM patients.

\section{Conflicts of Interest}

The authors declare that they have no conflicts of interest.

\section{References}

[1] S. Tesfaye, A. J. Boulton, P. J. Dyck et al., "Diabetic neuropathies: update on definitions, diagnostic criteria, estimation of severity, and treatments," Diabetes Care, vol. 33, no. 10, pp. 2285-2293, 2010.

[2] S. D. Candrilli, K. L. Davis, H. J. Kan, M. A. Lucero, and M. D. Rousculp, "Prevalence and the associated burden of illness of 
symptoms of diabetic peripheral neuropathy and diabetic retinopathy," Journal of Diabetes and Its Complications, vol. 21, no. 5, pp. 306-314, 2007.

[3] A. Gordois, P. Scuffham, A. Shearer, A. Oglesby, and J. A. Tobian, "The health care costs of diabetic peripheral neuropathy in the US," Diabetes Care, vol. 26, no. 6, pp. 1790-1795, 2003.

[4] J. de Jager, A. Kooy, P. Lehert et al., "Long term treatment with metformin in patients with type 2 diabetes and risk of vitamin B-12 deficiency: randomised placebo controlled trial," British Medical Journal, vol. 340, article c2181, 2010.

[5] R. Z. Ting, C. C. Szeto, M. H. Chan, K. K. Ma, and K. M. Chow, "Risk factors of vitamin B12 deficiency in patients receiving metformin," Archives of Internal Medicine, vol. 166, no. 18, pp. 1975-1979, 2006.

[6] M. Nervo, A. Lubini, F. V. Raimundo et al., "Vitamin B12 in metformin-treated diabetic patients: a cross-sectional study in Brazil," Revista da Associação Médica Brasileira, vol. 57, no. 1, pp. 46-49, 2011.

[7] L. S. Hermann, B. Nilsson, and S. Wettre, "Vitamin B12 status of patients treated with metformin: a cross-sectional cohort study," British Journal of Diabetes and Vascular Disease, vol. 4, pp. 401-404, 2004.

[8] M. C. Pflipsen, R. C. Oh, A. Saguil, D. A. Seehusen, D. Seaquist, and R. Topolski, "The prevalence of vitamin $\mathrm{B}_{12}$ deficiency in patients with type 2 diabetes: a cross-sectional study," Journal of American Board of Family Medicine, vol. 22, no. 5, pp. 528534, 2009.

[9] American Diabetes Association, "8. Pharmacologic approaches to glycemic treatment," Diabetes Care, vol. 40, Supplement 1, pp. S64-S74, 2017.

[10] G. T. Russo, A. Di Benedetto, D. Magazzu et al., "Mild hyperhomocysteinemia, $\mathrm{C}_{77} \mathrm{~T}$ polymorphism on methylenetetrahydrofolate reductase gene and the risk of macroangiopathy in type 2 diabetes: a prospective study," Acta Diabetologica, vol. 48, no. 2, pp. 95-101, 2011.

[11] E. B. Healton, D. G. Savage, J. C. Brust, T. J. Garrett, and J. Lindenbaum, "Neurologic aspects of cobalamin deficiency," Medicine (Baltimore), vol. 70, no. 4, pp. 229-245, 1991.

[12] C. Briani, C. Dalla Torre, V. Citton et al., "Cobalamin deficiency: clinical picture and radiological findings," Nutrients, vol. 5, no. 11, pp. 4521-4539, 2013.

[13] S. Chen, A. J. Lansdown, S. J. Moat et al., "An observational study of the effect of metformin on B12 status and peripheral neuropathy," British Journal of Diabetes and Vascular Disease, vol. 12, pp. 189-193, 2012.

[14] M. A. Ahmed, G. Muntingh, and P. Rheeder, "Vitamin B12 deficiency in metformin-treated type- 2 diabetes patients, prevalence and association with peripheral neuropathy," BMC Pharmacology and Toxicology, vol. 17, no. 1, p. 44, 2016.

[15] D. J. Wile and C. Toth, "Association of metformin, elevated homocysteine, and methylmalonic acid levels and clinically worsened diabetic peripheral neuropathy," Diabetes Care, vol. 33, no. 1, pp. 156-161, 2010.

[16] A. K. Singh, A. Kumar, D. Karmakar, and R. K. Jha, “Association of B12 deficiency and clinical neuropathy with metformin use in type 2 diabetes patients," Journal of Postgraduate Medicine, vol. 59, no. 4, pp. 253-257, 2013.

[17] D. M. de Groot-Kamphuis, P. R. van Dijk, K. H. Groenier, S. T. Houweling, H. J. Bilo, and N. Kleefstra, "Vitamin B12 deficiency and the lack of its consequences in type 2 diabetes patients using metformin," The Netherlands Journal of Medicine, vol. 71, no. 7, pp. 386-390, 2013.

[18] E. Biemans, H. E. Hart, G. E. Rutten, V. G. Cuellar Renteria, A. M. Kooijman-Buiting, and J. W. Beulens, "Cobalamin status and its relation with depression, cognition and neuropathy in patients with type 2 diabetes mellitus using metformin," Acta Diabetologica, vol. 52, no. 2, pp. 383-393, 2014.

[19] G. T. Russo, A. Giandalia, E. L. Romeo et al., "Diabetic neuropathy is not associated with homocysteine, folate, vitamin $B_{12}$ levels, and MTHFR $\mathrm{C6}_{77}$ T mutation in type 2 diabetic outpatients taking metformin," Journal of Endocrinological Investigation, vol. 39, no. 3, pp. 305-314, 2016.

[20] R. P. Roy, K. Ghosh, M. Ghosh et al., "Study of vitamin $B_{12}$ deficiency and peripheral neuropathy in metformin-treated early type 2 diabetes mellitus," Indian Journal of Endocrinology and Metabolism, vol. 20, no. 5, pp. 631-637, 2016.

[21] Q. L. Mao-Ying, A. Kavelaars, K. Krukowski et al., "The anti-diabetic drug metformin protects against chemotherapyinduced peripheral neuropathy in a mouse model," PLoS One, vol. 9, no. 6, article e100701, 2014.

[22] O. K. Melemedjian, A. Khoutorsky, R. E. Sorge et al., "mTORC1 inhibition induces pain via IRS-1-dependent feedback activation of ERK," Pain, vol. 154, no. 7, pp. 10801091, 2013.

[23] O. K. Melemedjian, M. N. Asiedu, D. V. Tillu et al., "Targeting adenosine monophosphate-activated protein kinase (AMPK) in preclinical models reveals a potential mechanism for the treatment of neuropathic pain," Molecular Pain, vol. 7, p. 70, 2011.

[24] I. Ullah, N. Ullah, M. I. Naseer, H. Y. Lee, and M. O. Kim, "Neuroprotection with metformin and thymoquinone against ethanol-induced apoptotic neurodegeneration in prenatal rat cortical neurons," BMC Neuroscience, vol. 13, p. 11, 2012.

[25] J. Wang, D. Gallagher, L. M. DeVito et al., "Metformin activates an atypical PKC-CBP pathway to promote neurogenesis and enhance spatial memory formation," Cell Stem Cell, vol. 11, no. 1, pp. 23-35, 2012.

[26] M. Y. El-Mir, D. Detaille, G. R-Villanueva et al., "Neuroprotective role of antidiabetic drug metformin against apoptotic cell death in primary cortical neurons," Journal of Molecular Neuroscience, vol. 34, no. 1, pp. 77-87, 2008.

[27] S. P. Patil, P. D. Jain, P. J. Ghumatkar, R. Tambe, and S. Sathaye, "Neuroprotective effect of metformin in MPTPinduced Parkinson's disease in mice," Neuroscience, vol. 277, pp. 747-754, 2014.

[28] A. Taylor, A. H. Westveld, M. Szkudlinska et al., "The use of metformin is associated with decreased lumbar radiculopathy pain," Journal of Pain Research, vol. 6, pp. 755-763, 2013.

[29] J. Ma, H. Yu, J. Liu, Y. Chen, Q. Wang, and L. Xiang, "Metformin attenuates hyperalgesia and allodynia in rats with painful diabetic neuropathy induced by streptozotocin," European Journal of Pharmacology, vol. 764, pp. 599-606, 2015.

[30] S. K. Roy Chowdhury, D. R. Smith, A. Saleh et al., "Impaired adenosine monophosphate-activated protein kinase signalling in dorsal root ganglia neurons is linked to mitochondrial dysfunction and peripheral neuropathy in diabetes," Brain, vol. 135, Part 6, pp. 1751-1766, 2012.

[31] A. L. Bjorke Monsen and P. M. Ueland, "Homocysteine and methylmalonic acid in diagnosis and risk assessment from 
infancy to adolescence," The American Journal of Clinical Nutrition, vol. 78, no. 1, pp. 7-21, 2003.

[32] R. Obeid, "Metformin causing vitamin B12 deficiency: a guilty verdict without sufficient evidence," Diabetes Care, vol. 37, no. 2, pp. e22-e23, 2014.

[33] L. Reinstatler, Y. P. Qi, R. S. Williamson, J. V. Garn, and G. P. Oakley Jr., "Association of biochemical $B_{12}$ deficiency with metformin therapy and vitamin $B_{12}$ supplements: the National Health and Nutrition Examination Survey, 19992006," Diabetes Care, vol. 35, no. 2, pp. 327-333, 2012.

[34] E. Greibe, B. Trolle, M. V. Bor, F. F. Lauszus, and E. Nexo, "Metformin lowers serum cobalamin without changing other markers of cobalamin status: a study on women with polycystic ovary syndrome," Nutrients, vol. 5, no. 7, pp. 2475-2482, 2013.

[35] E. Greibe, J. W. Miller, S. H. Foutouhi, R. Green, and E. Nexo, "Metformin increases liver accumulation of vitamin B12-an experimental study in rats," Biochimie, vol. 95, no. 5, pp. 1062-1065, 2013.

[36] M. G. Wulffele, A. Kooy, P. Lehert et al., "Effects of short-term treatment with metformin on serum concentrations of homocysteine, folate and vitamin B12 in type 2 diabetes mellitus: a randomized, placebo-controlled trial," Journal of Internal Medicine, vol. 254, no. 5, pp. 455-463, 2003.

[37] Y. Sato, K. Ouchi, Y. Funase, K. Yamauchi, and T. Aizawa, "Relationship between metformin use, vitamin B12 deficiency, hyperhomocysteinemia and vascular complications in patients with type 2 diabetes," Endocrine Journal, vol. 60, no. 12, pp. 1275-1280, 2013.

[38] E. K. Hoogeveen, P. J. Kostense, C. Jakobs, L. M. Bouter, R. J. Heine, and C. D. Stehouwer, "Does metformin increase the serum total homocysteine level in non-insulindependent diabetes mellitus?," Journal of Internal Medicine, vol. 242, no. 5, pp. 389-394, 1997.

[39] S. P. Stabler, R. H. Allen, L. P. Fried et al., "Racial differences in prevalence of cobalamin and folate deficiencies in disabled elderly women," The American Journal of Clinical Nutrition, vol. 70, no. 5, pp. 911-919, 1999.

[40] S. Saxena and R. Carmel, "Racial differences in vitamin B12 levels in the United States," American Journal of Clinical Pathology, vol. 88, no. 1, pp. 95-97, 1987.

[41] H. G. Kwee, H. S. Bowman, and L. W. Wells, "A racial difference in serum vitamin B12 levels," Journal of Nuclear Medicine, vol. 26, no. 7, pp. 790-792, 1985.

[42] F. Fernandes-Costa and J. Metz, "A comparison of serum transcobalamin levels in white and black subjects," The American Journal of Clinical Nutrition, vol. 35, no. 1, pp. 83-86, 1982. 


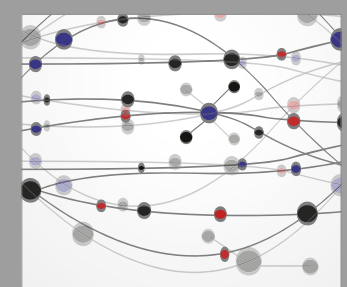

The Scientific World Journal
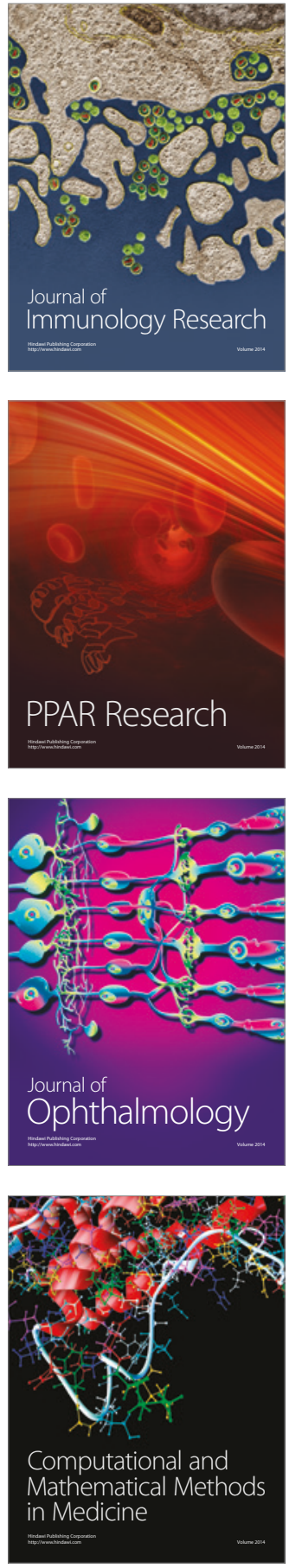

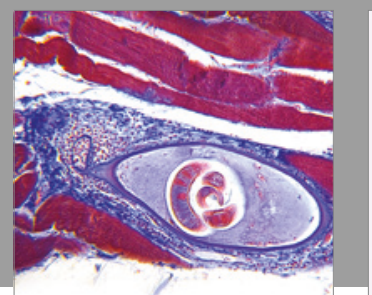

Gastroenterology Research and Practice
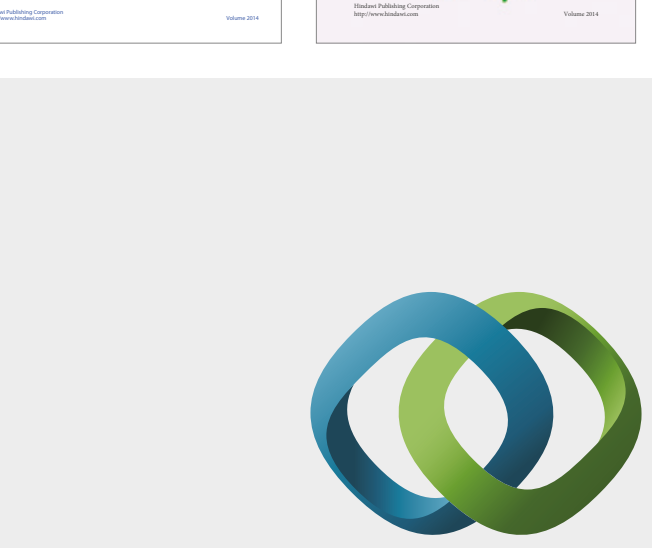

\section{Hindawi}

Submit your manuscripts at

https://www.hindawi.com
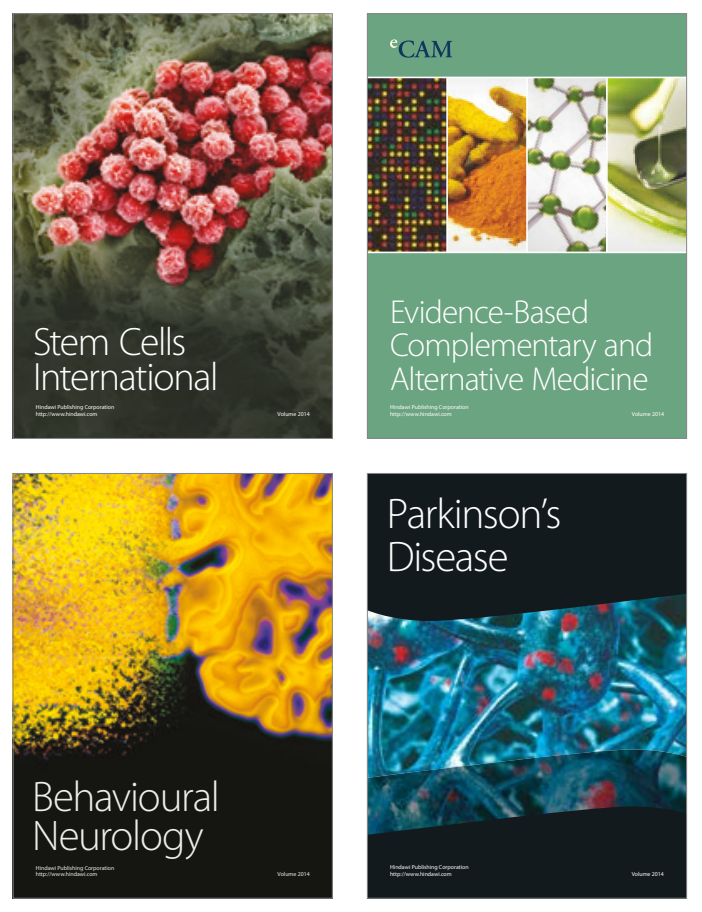
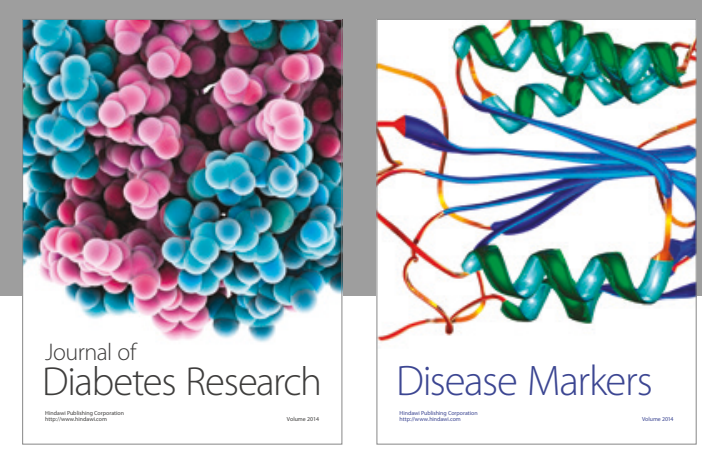

Disease Markers
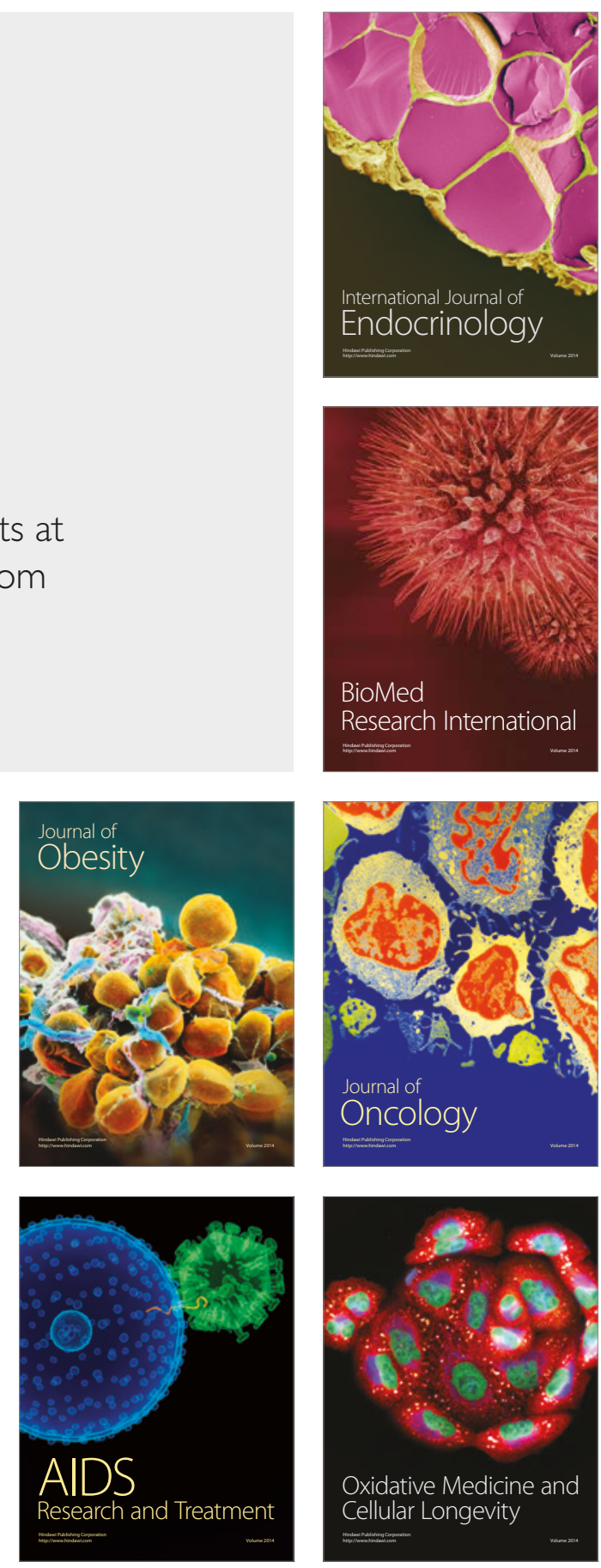